\title{
Thoracolumbar instrumentation with CT-guided navigation (O-arm) in 270 consecutive patients: accuracy rates and lessons learned
}

\author{
Mark A. Rivkin, D.O., M.Sc., and Steven S. Yocom, D.O. \\ Department of Neurosurgery, Cooper University Hospital, Camden, New Jersey
}

Object. Thoracolumbar instrumentation has experienced a dramatic increase in utilization over the last 2 decades. However, pedicle screw fixation remains a challenging undertaking, with suboptimal placement contributing to postoperative pain, neurological deficit, vascular complications, and return to the operating suite. Image-guided spinal surgery has substantially improved the accuracy rates for these procedures. However, it is not without technical challenges and a learning curve for novice operators. The authors present their experience with the O-arm intraoperative imaging system and share the lessons they learned over nearly 5 years.

Methods. The authors performed a retrospective chart review of 270 consecutive patients who underwent thoracolumbar pedicle screw fixation utilizing the O-arm imaging system in conjunction with StealthStation navigation between April 2009 and September 2013 at a single tertiary care center; 266 of the patients underwent CT scanning on postoperative Day 1 to evaluate hardware placement. The CT scans were interpreted prospectively by 3 neuroradiologists as part of standard work flow and retrospectively by 2 neurosurgeons and a senior resident. Pedicle screws were evaluated for breaches according to the 3 -tier classification proposed by Mirza et al.

Results. Of 270 patients, $266(98.5 \%)$ were included in the final analysis based on the presence of a postoperative CT scan. Overall, 1651 pedicle screws were placed in 266 patients and yielded a $5.3 \%$ breach rate; 213 thoracic and 1438 lumbosacral pedicle screws were inserted with $6.6 \%$ and $5.1 \%$ breach rates, respectively. Of the 87 suboptimally placed screws, there were 13 Grade 1,16 Grade 2, and 12 Grade 3 misses as well as 46 anterolateral or "tipout" perforations at L-5. Four patients (1.5\%) required a return to the operating room for pedicle screw revision, 2 of whom experienced transient radicular symptoms and 2 remained asymptomatic. Interestingly, the pedicle breach rate was higher than anticipated at $13.21 \%$ for the 30 patients over the initial 6-month period with the O-arm. After certain modifications to the authors' technique, the subsequent 30 patients experienced a statistically significant decrease in breach rate at $5.6 \%(\mathrm{p}=0.014)$.

Conclusions. Image-guided spinal surgery can be a great option in the operating room and provides high pedicle screw accuracy rates. With numerous systems commercially available, it is important to develop a systematic approach regardless of the technology in question. There is a learning curve for surgeons unfamiliar with image guidance that should be recognized and appreciated when transitioning to navigation-assisted spinal surgery. In fact, the authors' experience with a large patient cohort suggests that this learning curve may be more significant than previously reported.

(http://thejns.org/doi/abs/10.3171/2014.1.FOCUS13499)

\section{KeY WoRdS • thoracolumbar • image-guided • spinal navigation • O-arm}

I NSTRUMENTED thoracolumbar procedures have experienced a dramatic increase in the US over the last 2 decades. Rajaee et al. ${ }^{18}$ reported a 1.8 - and 2.7 -fold spike in thoracic and lumbar fusions, respectively, between 1998 and 2008. While pedicle screw (PS) fixation is widely believed to improve fusion rates, ${ }^{2,3}$ it remains a challenging endeavor with inadequate screw placement potentially resulting in postoperative pain, neurological injury, vascular complications, and return to the operating suite.

Multiple reports suggest that intraoperative spinal navigation offers increased accuracy of PS placement. ${ }^{4,6,17,25,27}$ Consequently, image-guided spinal surgery

\footnotetext{
Abbreviations used in this paper: IGSS = image-guided spinal surgery; PS = pedicle screw.
}

(IGSS) has gained much momentum as an adjunct to instrumented thoracolumbar procedures. Currently, numerous fluoroscopic (2D) and CT (3D) guidance systems are commercially available. The CT-based systems have been demonstrated to be superior with accuracy rates reaching the high $90 \mathrm{~s} .{ }^{21,26,27}$

However, intraoperative CT-guided spinal surgery is not without technical challenges. Inadvertent movement of registration markers, changes in patient anatomy after registration, and failure to maintain all tracking components visible to the camera, as well as limited field of view in multilevel procedures, have all been reported as potential disadvantages of IGSS. ${ }^{10}$ For novice operators, initial experience with image guidance may not immediately demonstrate the same high rates of PS placement accuracy widely quoted in the literature. 
We present our experience with IGSS using O-arm (Medtronic, Inc.) intraoperative imaging in conjunction with the StealthStation navigation system (Medtronic Navigation). First, we report PS placement accuracy rates in what, to our knowledge, is the largest, single-center cohort of image-guided thoracolumbar instrumentation utilizing the O-arm. Second, we present our learning curve associated with this technology, and we discuss the lessons learned during our initial experience with IGSS.

\section{Methods}

This study gained approval from the institutional review board. We integrated the $\mathrm{O}$-arm and StealthStation into our operating suite in the spring of 2009. Subsequently, the thoracolumbar-instrumented procedures were performed almost exclusively with CT imaging guidance. We retrospectively reviewed the charts of 270 consecutive patients from April 2009 to September 2013 who underwent O-arm-assisted surgery. Routine postoperative CT scans were obtained on postoperative Day 1 during this time period. We identified 4 patients with no such scan available for review, and instrumentation in these patients was excluded from the final analysis. Overall, 2 senior neurosurgeons placed 1665 pedicle screws over the course of the study utilizing the same surgical technique for all patients.

Patients underwent general anesthesia and were placed prone on the operating table. Once the surgeon completed the exposure and/or decompression as necessary, the O-arm was brought into the field to obtain images for CT-guided placement of instrumentation. The reference tracker was clamped 1-2 spinous processes cephalad to the levels of surgical pathology. The images were transferred to the StealthStation, and the O-arm was removed from the field in preparation for CT-based navigation. We first used an image-guided surface probe to confirm the starting point for each pedicle screw and then a high-speed bur to break through the cortex. Subsequently, an image-guided pedicle probe was used to enter the pedicle and was advanced to the desired depth using navigation. A ball probe was then used to investigate any potential pedicle breaches. Next, an image-guided tap was navigated in a similar fashion. After a second inspection with a ball probe, the pedicle screw was advanced in the same trajectory without image guidance. Navigation accuracy was rechecked prior to subsequent screw insertion by placing the image-guided surface probe at the next anatomical starting point. Screw length was determined in the operating suite once the pedicle probe was inserted to the desired depth by reading the measurements on the probe. Screw diameter was determined based on preoperative imaging.

Postoperative CT scans were interpreted without bias by 3 neuroradiologists as part of the standard workflow and retrospectively by 2 neurosurgeons and a senior resident. In cases of interobserver disagreement, the screw was preferentially assigned to the highest perforation grade. The 2 neurosurgeons were blinded as to who performed the procedure during their retrospective evaluation while the resident was not. In total, 1651 pedicle screws were evaluated for breaches according to the classification proposed by Mirza et al. ${ }^{11}$ Pedicle breaches were categorized as Grades 1, 2, and 3 when the screw perforated bone margins by $<2 \mathrm{~mm}, 2-4 \mathrm{~mm}$, and $>4$ $\mathrm{mm}$, respectively. We further recorded the direction of the breach as well as "tip-out," that is, anterior/anterolateral perforations most commonly encountered at L-5. In our practice, we aim for bicortical placement of S-1 screws and hence did not consider those as breaches.

\section{Statistical Analysis}

All statistical analyses were performed using SPSS (version 15.0.1, IBM, Inc.). Pearson chi-square and Fisher exact tests were used to compare variables that were proportions. The Fisher exact test was used when there were small samples ( $<5$ expected value). An independent t-test was used to compare means between groups. A p value $<$ 0.05 was considered statistically significant.

\section{Results}

Between April 2009 and September 2013, 270 charts of consecutive patients who underwent thoracolumbar instrumented procedures with the aid of the $\mathrm{O}$-arm were retrospectively reviewed (Table 1). The mean age of the patient cohort was $51.7 \pm 14.2$ years. Postoperative CT scans were obtained in 266 patients $(98.5 \%)$ on postoperative Day 1. Two hundred twenty-two operations were performed for degenerative pathology (82.2\%), 34 subsequent to trauma (12.6\%), 12 for tumor (4.4\%), and 2 for infection $(0.8 \%)$. In total, 1651 PSs were placed in these patients: 213 in the thoracic spine (12.9\%) and 1438 in the lumbar spine $(87.1 \%)$. Four patients $(1.5 \%)$ required a return to the operating room for revision of 4 PSs $(0.2 \%)$. In 2 cases, the patients experienced transient radicular symptoms that resolved after screw reposition. The first revision occurred in a 67-year-old man who was taken back for a lateral Grade 3 breach in the left L-5 PS after complaining of a new sensory deficit in the left leg (Fig. 1). The second revision was in a 50 -year-old woman who developed new radicular pain as a result of a left L-5 PS that demonstrated inferior Grade 2 breach (Fig. 2). In the

\section{TABLE 1: Findings at chart review for 270 patients*}

\begin{tabular}{lc}
\hline \multicolumn{1}{c}{ Parameter } & Value \\
\hline no. of patients & 270 \\
mean age in yrs \pm SD & $51.7 \pm 14.2$ \\
no. w/ postop CT scans (\%) & $266(98.5)$ \\
no. returned to OR (\%) & $4(1.5)$ \\
total no. of PSs & 1651 \\
breach (\%) & $87(5.3)$ \\
no. of thoracic PSs & 213 \\
breach (\%) & $14(6.6)$ \\
lumbar PSs & 1438 \\
breach $(\%)$ & $73(5.1)$ \\
\hline
\end{tabular}

* OR = operating room. 


\section{Image-guided pedicle screw placement utilizing the O-arm}

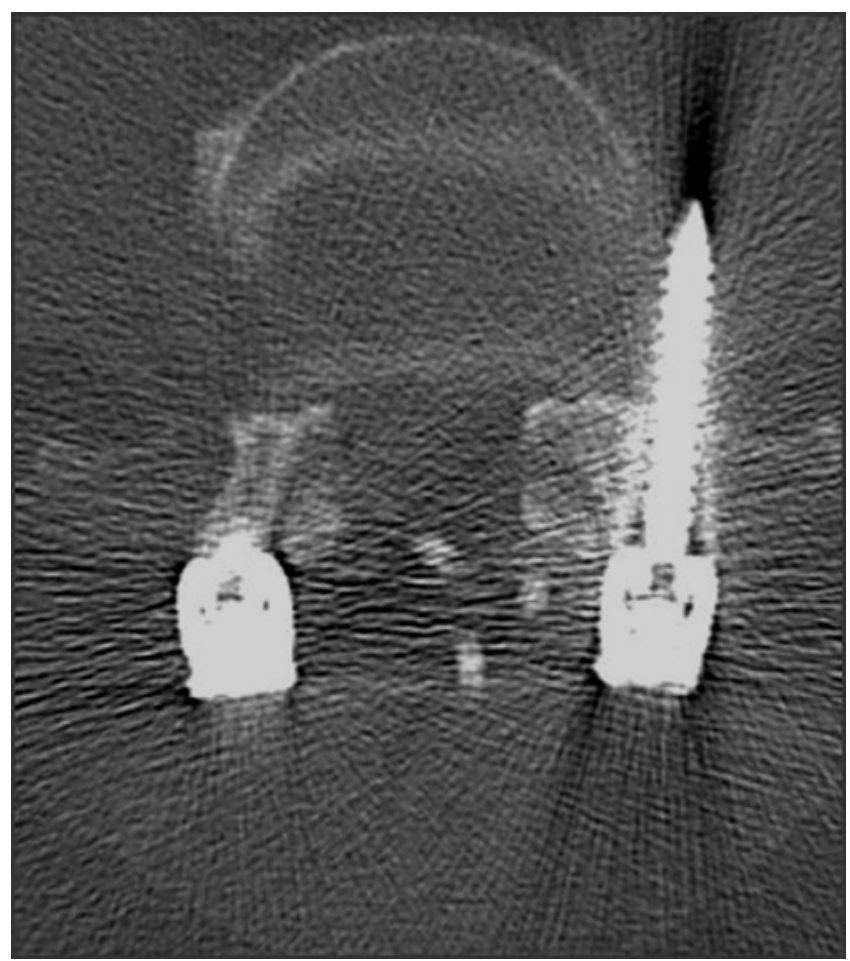

FIG. 1. Axial CT scan showing a Grade 3 lateral breach of the left $L-5$ pedicle screw. A new sensory deficit was noted postoperatively, which resolved after repositioning of the screw.

third revision case, the right S-1 PS was placed $13 \mathrm{~mm}$ beyond the anterior sacral cortical margin (Fig. 3). This patient remained asymptomatic but was taken to the operating room to back out the screw at the discretion of the treating spine surgeon. The forth revision was in a 30 -year-old woman who was asymptomatic and had a left T-4 PS that breached laterally by $>4 \mathrm{~mm}$ (Fig. 4).

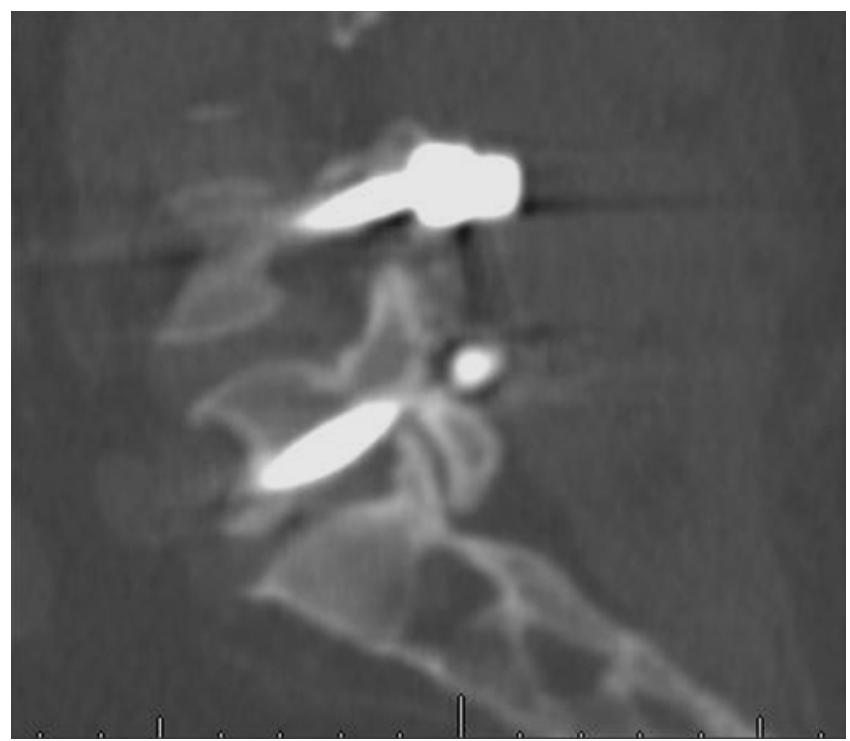

FIG. 2. Sagittal CT scan showing a Grade 2 inferior breach of the left $L-5$ pedicle screw. The patient reported new radicular pain in the L-5 distribution, which resolved immediately after repositioning of the screw.

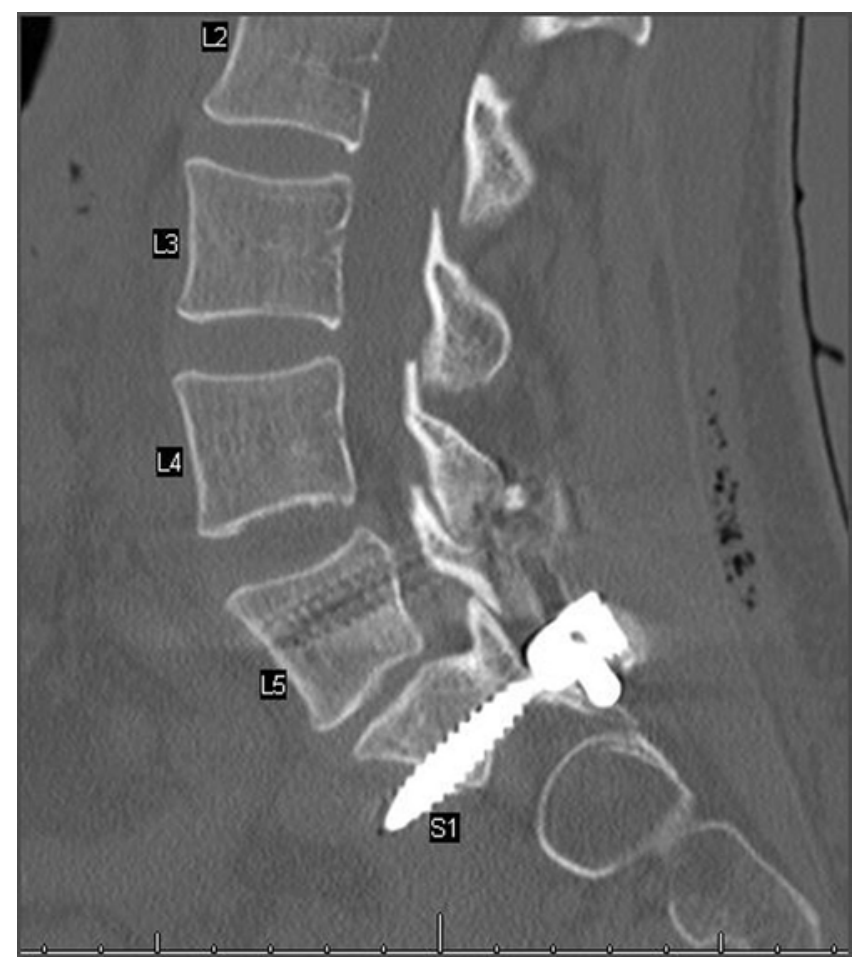

FIG. 3. Sagittal CT scan showing the right S-1 pedicle screw located $13 \mathrm{~mm}$ beyond the anterior cortical margin. The patient remained asymptomatic. Although bicortical placement of S-1 screws was preferred, this was deemed suboptimal by the treating surgeon and the patient was taken to the operating room to back out the screw.

The overall breach rate was $5.3 \%$, with thoracic PS yielding $6.6 \%$ and lumbar PS registering $5.1 \%$ of breaches. There were 87 total screws that were deemed suboptimal (Table 2). Among these, 13 PSs (14.9\%) were Grade 1 perforations, $16(18.4 \%)$ were Grade 2, 12 (13.8\%) were Grade 3, and $46(52.9 \%)$ were tip-out misses at L-5. Fifty-nine PSs $(67.8 \%)$ were considered either Grade 1 or tip-out misses. Excluding 46 anterolateral tip-out breaches, 24 of the remaining 41 suboptimally placed screws missed laterally $(58.5 \%)$ while only $9(21.6 \%)$ missed medially (Table 3). There were no differences among patients harboring breached screws compared with those without breaches with regard to age or sex (Table 4). The most common instrumented levels were L-4 (22.8\%), L-5 (25.4\%), and S-1 (17.6\%). Including tip-out L-5 breaches, the perforation rate for L-5 PS was the highest for any lumbar level at $13.6 \%$. However, excluding tip-out misses, there were 11 Grade $1-3$ breaches for a rate of $2.6 \%$. In the thoracic spine, T-7 level demonstrated the highest breach rate at $20 \%$, with 2 of 10 screws missing the pedicle, followed by T-6 at $17.6 \%$, with 3 of 17 screws placed suboptimally.

Pedicle breach rates were further evaluated with respect to our experience with the technology. The first 15 patients, or approximately 3 initial months' worth of cases, demonstrated a suboptimal accuracy rate of $82.9 \%$. At this point, we reexamined our technique over the next 3 months and implemented certain modifications that resulted in an accuracy rate of $90 \%$ in the subsequent 15 patients (Table 5). This trend was maintained as the next 


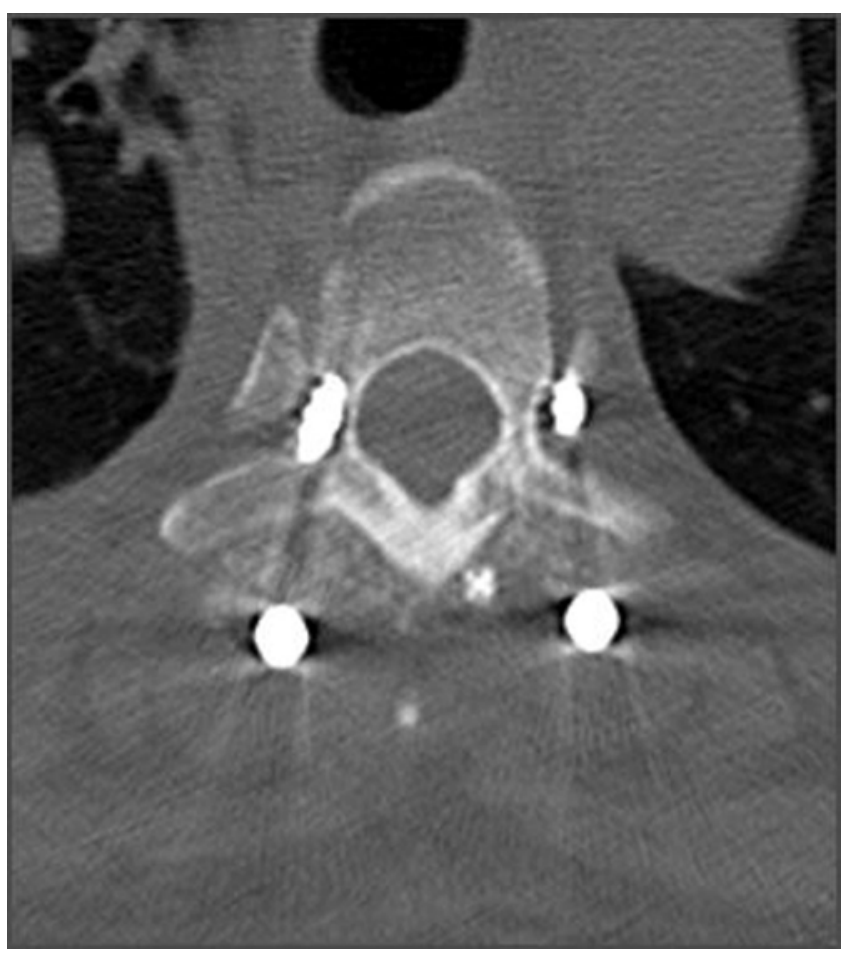

FIG. 4. Axial CT scan showing a Grade 3 breach of the left T-4 pedicle screw. This patient remained without symptoms but was taken to the operating room at the discretion of the treating surgeon to improve fixation, as this screw was near the top of the construct.

two same-sized groups demonstrated $92.9 \%$ and $95.9 \%$ successful placement rates. However, the trends between these groups did not reach statistical significance.

However, a statistically significant difference in perforations was observed between the first group of 30 patients, or approximately the initial 6 months with the $\mathrm{O}$-arm, at $13.21 \%$ and the next group of the same size at $5.6 \%(\mathrm{p}=0.014)($ Fig. 5). There were 21 total missed screws among the inaugural group of 30 patients, which constituted $24.1 \%$ of all missed PSs in the study. The next consecutive group of same size contained 11 perforations, or $12.6 \%$ of total missed PSs. Twelve tip-out breaches $(7.5 \%)$ were noted in the first group while 7 such breaches (3.6\%) appeared in the next group, which failed to reach statistical significance $(p=0.153)$. Excluding tipout misses, there were 9 Grade $1-3$ breaches $(5.7 \%)$ in the first group while 4 such breaches $(2.1 \%)$ occurred in the second group $(p=0.091)$. In fact, comparing the accuracy rate for the initial 30 patients to any of the subsequent groups of same size, statistically significant inferiority is evident against all but one group.

\section{Discussion}

Computed tomography-based IGSS offers several advantages to the spine surgeon including greater accuracy of pedicle screw placement, ${ }^{4,6,21,24-27}$ minimal to no radiation exposure, ${ }^{12,15,21,22}$ and potentially a short registration time..$^{5,12-14}$ As with any new technology, CT-guided spinal surgery is prone to growing pains, which may force novice surgeons to abandon this technology early.
TABLE 2: Total number of PSs grouped by spinal level and breach grade

\begin{tabular}{|c|c|c|c|c|c|c|}
\hline \multirow[b]{2}{*}{ Level } & \multirow[b]{2}{*}{$\begin{array}{c}\text { Total No. } \\
\text { of PSs }\end{array}$} & \multirow[b]{2}{*}{$\begin{array}{c}\text { No. of } \\
\text { Breaches (\%) }\end{array}$} & \multicolumn{4}{|c|}{ No. of Breaches } \\
\hline & & & $\begin{array}{c}\text { Grade } \\
1\end{array}$ & $\begin{array}{c}\text { Grade } \\
2\end{array}$ & $\begin{array}{c}\text { Grade } \\
3\end{array}$ & Tip Out \\
\hline $\mathrm{T}-1$ & 8 & $1(12.5)$ & & 1 & & \\
\hline T-2 & 6 & 0 & & & & \\
\hline T-3 & 6 & $1(16.7)$ & 1 & & & \\
\hline $\mathrm{T}-4$ & 10 & $1(10)$ & & & 1 & \\
\hline T-5 & 14 & $1(7.1)$ & & & 1 & \\
\hline T-6 & 17 & $3(17.6)$ & 1 & 1 & 1 & \\
\hline $\mathrm{T}-7$ & 10 & $2(20)$ & & 1 & 1 & \\
\hline $\mathrm{T}-8$ & 26 & $3(11.5)$ & 1 & 1 & 1 & \\
\hline T-9 & 22 & 0 & & & & \\
\hline $\mathrm{T}-10$ & 28 & 0 & & & & \\
\hline $\mathrm{T}-11$ & 34 & $1(2.9)$ & 1 & & & \\
\hline $\mathrm{T}-12$ & 32 & $1(3.1)$ & & 1 & & \\
\hline L-1 & 54 & $2(3.7)$ & 2 & & & \\
\hline L-2 & 91 & $3(3.3)$ & 1 & 2 & & \\
\hline L-3 & 207 & $4(1.9)$ & & 2 & 2 & \\
\hline L-4 & 376 & $6(1.6)$ & 3 & 2 & 1 & \\
\hline$L-5$ & 420 & $57(2.6)$ & 3 & 4 & 4 & 46 \\
\hline S-1 & 290 & $1(0.3)$ & & 1 & & \\
\hline total & 1651 & $87(5.3)$ & 13 & 16 & 12 & 46 \\
\hline
\end{tabular}

Reports investigating the learning curve associated with CT image guidance are sparse. Nottmeier and Crosby acknowledged this phenomenon and hypothesized that 5 cases are necessary for surgeons with limited image guidance skills to obtain sufficient experience with this technology.$^{14}$ However, our experience suggests that perhaps a larger volume of approximately 15-30 cases is required to demonstrate breach rates similar to those commonly reported in the literature. To our knowledge, the present report is the largest single-center series of thoracolumbar PSs placed using the $\mathrm{O}$-arm and the first in the literature to quantify the learning curve for screw accuracy associated with this technology.

We demonstrated $5.3 \%$ overall, $6.6 \%$ thoracic, and $5.1 \%$ lumbosacral breach rates in our cohort of 1651 PSs placed with the aid of the $\mathrm{O}$-arm. These values fall within the previously published range utilizing similar technology. Tian and Xu performed a meta-analysis evaluating more than 7500 PSs and noted a nearly 91\% accuracy rate with CT-assisted navigation. ${ }^{24}$ Gelalis et al. reviewed 26 prospective trials comparing various methods for PS placement. In the subgroup of CT-guided navigation, the authors reported a range of $89 \%-100 \%$ of screws contained completely within a pedicle. ${ }^{4}$ In a retrospective study, Waschke et al. used a Tomoscan M-EG (Philips Medical Systems) to place 2422 PSs with $96.4 \%$ accuracy in the lumbar spine and $95.5 \%$ in the thoracic spine. ${ }^{27}$ In another retrospective review, Nottmeier et al. reported on 184 patients and 951 thoracolumbar screws placed with CT-based navigation and a 7.5\% breach rate. ${ }^{16}$ In a large 
Image-guided pedicle screw placement utilizing the O-arm

TABLE 3: Pedicle screw breaches by direction excluding tip-out L-5 screws

\begin{tabular}{|c|c|c|c|c|c|c|}
\hline \multirow[b]{2}{*}{ Level } & \multirow{2}{*}{$\begin{array}{c}\text { Total No. of } \\
\text { Breaches }\end{array}$} & \multicolumn{5}{|c|}{ No. of Breaches } \\
\hline & & Medial & Lat & Inferior & Superior & Anterior \\
\hline T-1 & 1 & & 1 & & & \\
\hline \multicolumn{7}{|l|}{$\mathrm{T}-2$} \\
\hline T-3 & 1 & & 1 & & & \\
\hline $\mathrm{T}-4$ & 1 & & 1 & & & \\
\hline T-5 & 1 & & 1 & & & \\
\hline T-6 & 3 & & 2 & 1 & & \\
\hline $\mathrm{T}-7$ & 2 & & 1 & & & 1 \\
\hline $\mathrm{T}-8$ & 3 & 2 & & & 1 & \\
\hline \multicolumn{7}{|l|}{ T-9 } \\
\hline \multicolumn{7}{|l|}{$\mathrm{T}-10$} \\
\hline $\mathrm{T}-11$ & 1 & 1 & & & & \\
\hline $\mathrm{T}-12$ & 1 & 1 & & & & \\
\hline L-1 & 2 & & 1 & & & 1 \\
\hline L-2 & 3 & 1 & 2 & & & \\
\hline L-3 & 4 & 2 & 2 & & & \\
\hline L-4 & 6 & 1 & 5 & & & \\
\hline L-5 & 11 & 1 & 6 & 4 & & \\
\hline S-1 & 1 & 0 & 1 & & & \\
\hline total & 41 & 9 & 24 & 5 & 1 & 2 \\
\hline
\end{tabular}

cohort utilizing the O-arm, Larson et al. placed 984 PSs in 50 pediatric patients undergoing deformity surgery with a $96.4 \%$ accuracy rate as well as 1511 PSs in adult patients with a $98.2 \%$ accuracy rate. ${ }^{7}$

We identified 2 prospective trials utilizing the $\mathrm{O}$-arm for pedicle screw placement. Shin et al. described 124 PSs placed between T-9 and S-1. The authors reported that nearly $92 \%$ of the PSs were contained completely within the pedicle. ${ }^{21}$ Van de Kelft et al. presented their experience with the $\mathrm{O}$-arm in a multicenter trial that included 1922 screws in 353 patients. The authors experienced a $97.5 \%$ accuracy rate in this large cohort. ${ }^{26}$

However, little mention is made in the literature regarding early experiences of navigation-naive spine surgeons with CT-assisted image guidance. At our institution, the implementation of the $\mathrm{O}$-arm constituted a paradigm shift in the surgical suite as we did not use any spinal navigation systems previously. We anticipated an increase in surgical times for the initial procedures performed with the O-arm. Interestingly, we also observed a lower than anticipated accuracy rate over the first 3 months, with $17 \%$ of screws breaching during the first 15 cases. This introductory experience forced us to critically evaluate all aspects of image guidance utilization in the operating room, which facilitated several modifications to our technique. After implementing these adaptations over the next 3 months, we observed an incremental increase in the accuracy rate in the subsequent 15 cases. In fact, comparing screws completely contained within the pedicle between the initial 30 cases ( $86 \%$ accuracy rate) and the next group of the same size (94\% accuracy rate) proved to be statistically significant $(\mathrm{p}=0.014)$. More-
TABLE 4: Differences in age and sex

\begin{tabular}{lccc}
\hline \multicolumn{1}{c}{ Variable } & Breach & No Breach & p Value \\
\hline $\begin{array}{l}\text { no. of screws } \\
\text { sex }\end{array}$ & 87 & $1560^{*}$ & \\
no. in males (\%) & $34(39.1)$ & $710(45.5)$ & 0.241 \\
$\quad$ no. in females (\%) & $53(60.9)$ & $850(54.5)$ & \\
mean patient age in & $53.28 \pm 14.33$ & $52.89 \pm 14.64$ & 0.809 \\
$\quad$ yrs \pm SD & & & \\
\hline * There were missing data at final analysis for 1 patient (4 screws). \\
Therefore, these screws are not included in this analysis.
\end{tabular}

over, we were able to maintain this high rate for the duration of the study.

We would like to share the technical lessons learned from our initial experience with the $\mathrm{O}$-arm that were instrumental in eventually achieving and maintaining high PS placement accuracy. These operational nuances are the result of trial-and-error experimentation in our operating suite. First, the position of the reference tracker should be such that is it easily visible by the StealthStation camera. This becomes increasingly important when multiple instruments and surgeons' hands are in the surgical field as they may transiently interfere with the visibility of the tracker. For this reason, we prefer to always position the tracker at the cranial aspect of the incision, tilting it away from the surgical field (Fig. 6). This configuration allows for the tracker to be easily visible to the camera that is positioned 4-6 feet away from the incision and over the anesthesia drapes. We found this arrangement to be easier than positioning the camera and the tracker caudally as this orientation in our experience resulted in more line-of-sight interference from the surgeon and surgical instruments, as well as the setup of the surgical technician (Fig. 7).

Another important technical aspect is the proximity of the reference tracker to the surgical field. We prefer to clamp the tracker onto a spinous process of the cranial vertebral segment utilizing the same surgical incision. Placing the tracker too far from the levels requiring instrumentation may compromise accuracy. However, a tracker position too close to the pathological levels, or not tilted away from the field, may potentiate accidental contact between the tracker and surgical instruments. Compromised visibility of image-guided instruments or diminished accuracy of the navigation system can occur with each subsequent accidental contact. This becomes especially important near the lumbosacral junction where caudally directed pedicles of L-5 and S-1 may facilitate

TABLE 5: Accuracy rates by 15-patient increments

\begin{tabular}{cccc}
\hline No. of Patients & Total No. of PSs & No. of Breaches & $\%$ Accuracy \\
\hline $0-15$ & 70 & 12 & 82.9 \\
$16-30$ & 89 & 9 & 90 \\
$31-45$ & 98 & 7 & 92.9 \\
$46-60$ & 97 & 4 & 95.9 \\
\hline
\end{tabular}




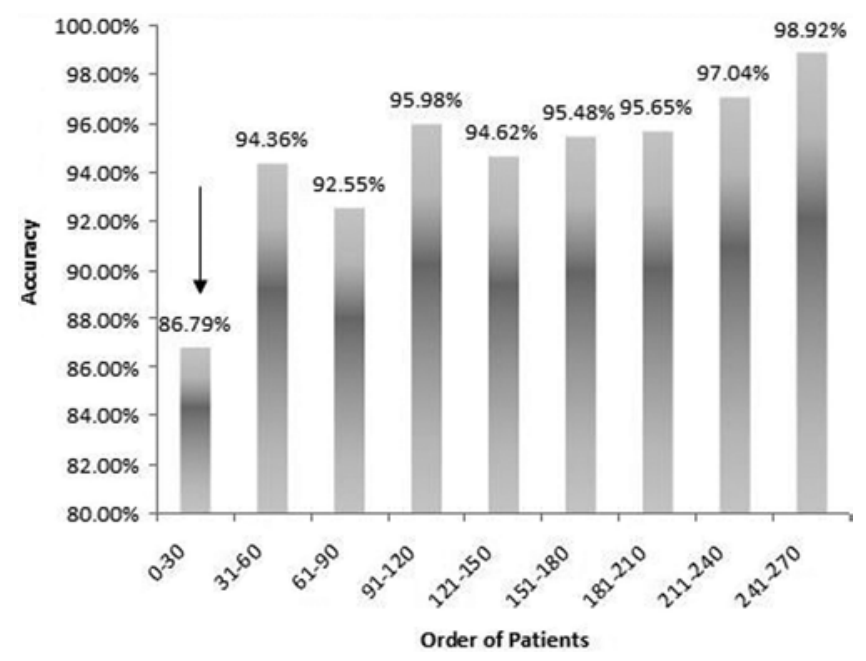

FIG. 5. Accuracy rates by 30 -patient increments. The arrow indicates a statistically significant difference between the first and second group of patients $(p=0.014)$.

the surgical instrumentation to bump the spinous process clamp much more so than with cranially directed pedicles of the upper and middle lumbar spine. We initially affixed the tracker at the spinous process one level cranial to spinal levels of interest. However, we noticed that accidental contact between larger instruments and the tracker was not infrequent. We believe that this partially facilitated our early suboptimal PS placement accuracy rates by allowing for excessive tip-out perforations at L-5. Conversely, the technique was modified by slightly extending the incision to clamp the tracker onto 2 spinous processes cranially to the involved levels. Care is taken to preserve the integrity of the posterior ligamentous complex during exposure and only the spinous process is exposed in a subperiosteal fashion. No attempt is made to expose the lamina or the facet capsules in an attempt to minimize adjacent-segment disease at those levels and postoperative discomfort. In our experience, this modification achieves the necessary proximity to the surgical field and maintains the cosmetic advantages of a single incision while attenuating the interference between the reference tracker and surgical instruments.

Yet another source of screw breaches may be the length of the PS. During our initial experience, we relied on the intraoperative $\mathrm{O}$-arm scan and an image-guided pedicle probe to determine screw length. The probe was inserted to a desired depth under image guidance, and the screw length was chosen by the surgeon based on the reading on the pedicle probe. This technique resulted in placement of longer PSs than were necessary, with concomitant anterior and lateral breaches over this time period. Unfortunately, some of these breaches were not appreciated with the ball probe prior to screw insertion. One explanation for this is that an excessive downward force vector during attempts to cannulate the pedicle causes partial downward motion of the adjacent segments containing the reference tracker. Thus, the anterolateral border of the vertebral body appears "deeper" on the monitor. To address this discrepancy, screw sizes were selected based on preoperative images going forward. This was a

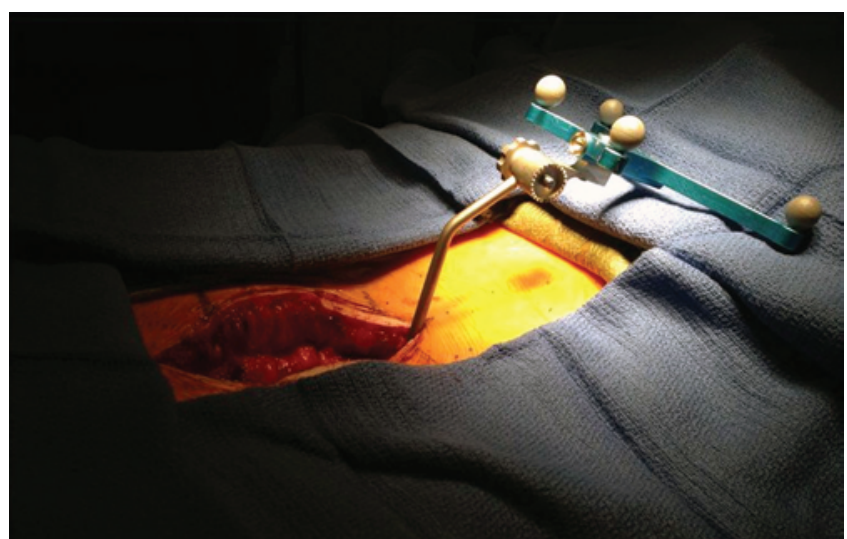

FIG. 6. Intraoperative photograph demonstrating the tracker attached at the cranial aspect of the incision and tilted away from the surgical field toward the camera.

simple modification with favorable results in subsequent procedures.

Furthermore, it is critical to decide whether instrumentation should be placed before or after performing other necessary components of the operation. Either way, hardware placement should occur immediately after the registration $\mathrm{O}$-arm scan is obtained without further decompression, reduction of fracture, or discectomy taking place after the scan prior to instrumenting. Although this

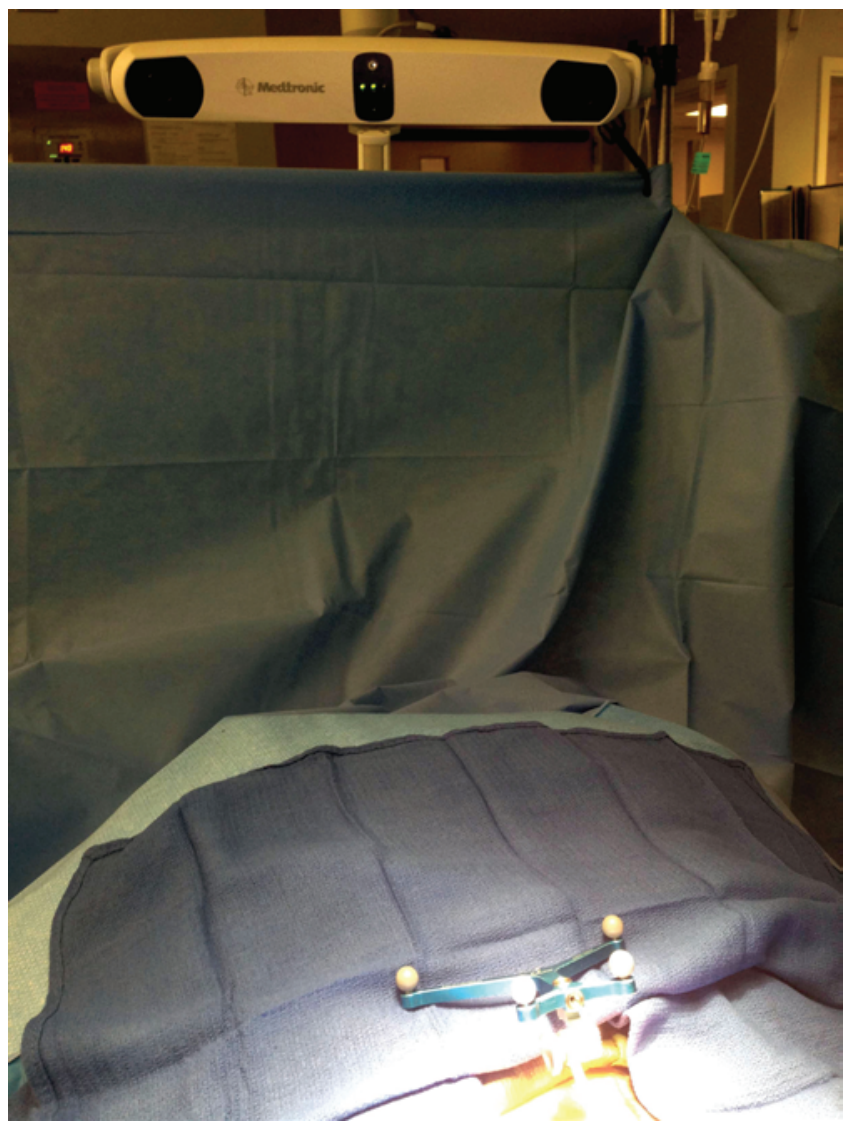

FIG. 7. Intraoperative photograph demonstrating the optimal position of the StealthStation camera at the head of the bed and the spinous process tracker to minimize line-of-site interference. 
may seem intuitive, segmental motion allows for a potential slight shift of vertebral segments with respect to each other during bone and disc space work. Should this occur after registration, it may lead to diminished screw accuracy and facilitate pedicle breaches. If the surgeon feels that further bone work is necessary after the registration, a second registration scan is recommended prior to PS insertion. This becomes particularly important in the midthoracic spine where pedicle width has been shown to decrease to just under $4 \mathrm{~mm} .^{1,8}$ Since IGSS carries a reported mean registration error up to $2-3 \mathrm{~mm}$, any further changes to 3D anatomy subsequent to the registration scan may compromise PS accuracy rates. ${ }^{17,23}$

In the present cohort, we did not routinely perform intraoperative CT scanning after hardware placement. This resulted in 4 returns to the operating room over a 54-month period for a $1.5 \%$ reoperation rate secondary to malpositioned screws. Two patients $(0.7 \%)$ underwent reoperation for new-onset radicular symptoms. Given the retrospective nature of our study, it is difficult to determine the circumstances for revisions in the other 2 asymptomatic patients.

The decision to proceed without a postinstrumentation scan was based on several factors. We instrumented a relatively small number of levels per patient in this mostly degenerative spine fusion cohort. Moreover, intraoperative CT quality may be inferior to postoperative CT scanning and may not be sensitive enough to pick up small, that is, Grade 1 or 2 , breaches. ${ }^{20}$ In fact, 1 of the 4 patients who returned to the operating room had a Grade 2 breach that probably would not have been noticed on an intraoperative scan. Additionally, the majority of breaches reported in our series, namely tip-out breaches, would likely not have been revised even if they were confirmed by an intraoperative scan.

In cases in which navigation was determined to be inaccurate, reregistration prior to hardware placement took place. When there was a concern for loss of navigation accuracy while instrumenting as a result of bumping the tracker or any change in anatomy, another registration scan was obtained before proceeding with the remaining pedicle screws. However, in cases in which the registration appeared accurate and the ball probe palpation revealed no breaches, we felt that no intraoperative CT after instrumenting was necessary.

We concede that 3 of the 4 returns to the operating room $(1.1 \%)$ could have been potentially prevented by repositioning the screws after obtaining an intraoperative scan. Returns to the operating room are associated with increased cost and can be avoidable in this setting. Hence, after the data for this project were collected and reviewed, our protocol was modified to perform a scan prior to leaving the operating room.

Several studies reviewed revision rates secondary to suboptimal hardware placement. Larson et al. placed 984 thoracolumbar PSs for pediatric deformity and reported a $3.6 \%$ intraoperative revision rate after obtaining an intraoperative scan. ${ }^{7}$ No returns to the operating rooms occurred in this study. Similarly, Van de Kelft et al. revised $1.8 \%$ of PSs intraoperatively. ${ }^{26}$ Tormenti et al. also used intraoperative confirmation for PS screw placement, resulting in no returns to the operating room. ${ }^{25}$
In contrast, Nottmeier et al. reported 2 nerve root injuries after placing 1084 PSs, resulting in a $0.9 \%$ patient incidence. ${ }^{16}$ One of these injuries was not recognized with intraoperative imaging, and the patient was returned to the operating room to undergo revision surgery. In a large series, Lonstein et al. documented a $1.0 \%$ rate of PS revision in their experience with 875 patients. ${ }^{9}$ Most recently, Samdani et al. evaluated revision rates in 627 patients undergoing pediatric deformity procedures. ${ }^{19}$ The authors reported a $1.7 \%$ rate of returning to the operating room secondary to suboptimal screw position.

\section{Conclusions}

Image-guided spinal surgery provides high PS accuracy rates and is becoming more readily available in operating rooms across the world. However, as with any new technology, certain growing pains exist for novice operators of the $\mathrm{O}$-arm that must be overcome before results widely quoted in the literature can be reproduced. Our experience with a large patient cohort suggests that this learning curve may be greater than previously anticipated. Regardless of the surgeon's preference, we recommend developing a systematic approach to utilizing IGSS in the operating suite as this should maximize surgical outcomes.

\section{Disclosure}

The authors report no conflict of interest concerning the materials or methods used in this study or the findings specified in this paper. Dr. Yocom is a consultant for Orthofix and Precision Spine.

Author contributions to the study and manuscript preparation include the following. Conception and design: both authors. Acquisition of data: Rivkin. Analysis and interpretation of data: Rivkin. Drafting the article: Rivkin. Critically revising the article: both authors. Reviewed submitted version of manuscript: both authors. Approved the final version of the manuscript on behalf of both authors: Rivkin. Administrative/technical/material support: Yocom. Study supervision: Yocom.

\section{References}

1. Christodoulou AG, Apostolou T, Ploumis A, Terzidis I, Hantzokos I, Pournaras J: Pedicle dimensions of the thoracic and lumbar vertebrae in the Greek population. Clin Anat 18:404408, 2005

2. Fischgrund JS, Mackay M, Herkowitz HN, Brower R, Montgomery DM, Kurz LT: 1997 Volvo Award winner in clinical studies. Degenerative lumbar spondylolisthesis with spinal stenosis: a prospective, randomized study comparing decompressive laminectomy and arthrodesis with and without spinal instrumentation. Spine (Phila Pa 1976) 22:2807-2812, 1997

3. France JC, Yaszemski MJ, Lauerman WC, Cain JE, Glover $\mathrm{JM}$, Lawson KJ, et al: A randomized prospective study of posterolateral lumbar fusion. Outcomes with and without pedicle screw instrumentation. Spine (Phila Pa 1976) 24:553-560, 1999

4. Gelalis ID, Paschos NK, Pakos EE, Politis AN, Arnaoutoglou CM, Karageorgos AC, et al: Accuracy of pedicle screw placement: a systematic review of prospective in vivo studies comparing free hand, fluoroscopy guidance and navigation techniques. Eur Spine J 21:247-255, 2012

5. Holly LT, Foley KT: Image guidance in spine surgery. Orthop Clin North Am 38:451-461, 2007 
6. Kosmopoulos V, Schizas C: Pedicle screw placement accuracy: a meta-analysis. Spine (Phila Pa 1976) 32:E111-E120, 2007

7. Larson AN, Santos ER, Polly DW Jr, Ledonio CG, Sembrano $\mathrm{JN}$, Mielke $\mathrm{CH}$, et al: Pediatric pedicle screw placement using intraoperative computed tomography and 3-dimensional image-guided navigation. Spine (Phila Pa 1976) 37:E188E194, 2012

8. Liau KM, Yusof MI, Abdullah MS, Abdullah S, Yusof AH: Computed tomographic morphometry of thoracic pedicles: safety margin of transpedicular screw fixation in Malaysian Malay population. Spine (Phila Pa 1976) 31:E545-E550, 2006

9. Lonstein JE, Denis F, Perra JH, Pinto MR, Smith MD, Winter RB: Complications associated with pedicle screws. J Bone Joint Surg Am 81:1519-1528, 1999

10. Manbachi A, Cobbold RS, Ginsberg HJ: Guided pedicle screw insertion: techniques and training. Spine J 14:165-179, 2014

11. Mirza SK, Wiggins GC, Kuntz C IV, York JE, Bellabarba C, Knonodi MA, et al: Accuracy of thoracic vertebral body screw placement using standard fluoroscopy, fluoroscopic image guidance, and computed tomographic image guidance: a cadaver study. Spine (Phila Pa 1976) 28:402-413, 2003

12. Nottmeier EW, Bowman C, Nelson KL: Surgeon radiation exposure in cone beam computed tomography-based, imageguided spinal surgery. Int J Med Robot 8:196-200, 2012

13. Nottmeier EW, Crosby T: Timing of vertebral registration in three-dimensional, fluoroscopy-based, image-guided spinal surgery. J Spinal Disord Tech 22:358-360, 2009

14. Nottmeier EW, Crosby TL: Timing of paired points and surface matching registration in three-dimensional (3D) imageguided spinal surgery. J Spinal Disord Tech 20:268-270, 2007

15. Nottmeier EW, Pirris SM, Edwards S, Kimes S, Bowman C, Nelson KL: Operating room radiation exposure in cone beam computed tomography-based, image-guided spinal surgery. Clinical article. J Neurosurg Spine 19:226-231, 2013

16. Nottmeier EW, Seemer W, Young PM: Placement of thoracolumbar pedicle screws using three-dimensional image guidance: experience in a large patient cohort. Clinical article. $\mathbf{J}$ Neurosurg Spine 10:33-39, 2009

17. Papadopoulos EC, Girardi FP, Sama A, Sandhu HS, Cammisa FP Jr: Accuracy of single-time, multilevel registration in image-guided spinal surgery. Spine J 5:263-268, 2005

18. Rajaee SS, Bae HW, Kanim LE, Delamarter RB: Spinal fusion in the United States: analysis of trends from 1998 to 2008. Spine (Phila Pa 1976) 37:67-76, 2012

19. Samdani AF, Belin EJ, Bennett JT, Pahys JM, Marks MC, Mi- yanji $\mathrm{F}$, et al: Unplanned return to the operating room in patients with adolescent idiopathic scoliosis: are we doing better with pedicle screws? Spine (Phila Pa 1976) 38:1842-1847, 2013

20. Santos ER, Ledonio CG, Castro CA, Truong WH, Sembrano $\mathrm{JN}$ : The accuracy of intraoperative O-arm images for the assessment of pedicle screw postion. Spine (Phila Pa 1976) 37:E119-E125, 2012

21. Shin MH, Hur JW, Ryu KS, Park CK: Prospective comparison study between the fluoroscopy guided and navigation coupled with $\mathrm{O}-\mathrm{arm}^{\circledR}$ guided pedicle screw placement in the thoracic and lumbosacral spines. J Spinal Disord Tech [epub ahead of print], 2013

22. Smith HE, Welsch MD, Sasso RC, Vaccaro AR: Comparison of radiation exposure in lumbar pedicle screw placement with fluoroscopy vs computer-assisted image guidance with intraoperative three-dimensional imaging. J Spinal Cord Med 31:532-537, 2008

23. Takahashi J, Hirabayashi H, Hashidate H, Ogihara N, Kato H: Accuracy of multilevel registration in image-guided pedicle screw insertion for adolescent idiopathic scoliosis. Spine (Phila Pa 1976) 35:347-352, 2010

24. Tian NF, Xu HZ: Image-guided pedicle screw insertion accuracy: a meta-analysis. Int Orthop 33:895-903, 2009

25. Tormenti MJ, Kostov DB, Gardner PA, Kanter AS, Spiro RM, Okonkwo DO: Intraoperative computed tomography imageguided navigation for posterior thoracolumbar spinal instrumentation in spinal deformity surgery. Neurosurg Focus 28(3):E11, 2010

26. Van de Kelft E, Costa F, Van der Planken D, Schils F: A prospective multicenter registry on the accuracy of pedicle screw placement in the thoracic, lumbar, and sacral levels with the use of the O-arm imaging system and StealthStation Navigation. Spine (Phila Pa 1976) 37:E1580-E1587, 2012

27. Waschke A, Walter J, Duenisch P, Reichart R, Kalff R, Ewald $\mathrm{C}$ : CT-navigation versus fluoroscopy-guided placement of pedicle screws at the thoracolumbar spine: single center experience of 4,500 screws. Eur Spine J 22:654-660, 2013

Manuscript submitted November 4, 2013.

Accepted January 10, 2014.

Please include this information when citing this paper: DOI: 10.3171/2014.1.FOCUS13499.

Address correspondence to: Mark Rivkin, D.O., M.Sc., 32 Conshohocken State Rd., F-3, Bala Cynwyd, PA 19004. email: rivkin@ comcast.net. 